\title{
Clinical Correlates and Drug Resistance in HIV-Infected and -Uninfected Pulmonary Tuberculosis Patients in South India
}

\author{
Sara Chandy ${ }^{1 *}$, Elsa Heylen ${ }^{2}$, Baijayanti Mishra ${ }^{3}$, Maria Lennartsdotter Ekstrand ${ }^{2,4}$ \\ ${ }^{1}$ Department of Medicine, St John's Medical College, Bangalore, India \\ ${ }^{2}$ Center for AIDS Prevention Studies, University of California, San Francisco, USA \\ ${ }^{3}$ Department of Microbiology, St John's Medical College, Bangalore, India \\ ${ }^{4}$ St John's Research Institute, Bangalore, India \\ Email: *chandysara@gmail.com
}

How to cite this paper: Chandy, S., Heylen, E., Mishra, B. and Ekstrand, M.L. (2016) Clinical Correlates and Drug Resistance in HIV-Infected and -Uninfected Pulmonary Tuberculosis Patients in South India. Worla Journal of AIDS, 6, 87-100.

http://dx.doi.org/10.4236/wja.2016.63013

Received: July 19, 2016

Accepted: September 6, 2016

Published: September 9, 2016

Copyright $\odot 2016$ by authors and Scientific Research Publishing Inc. This work is licensed under the Creative Commons Attribution International License (CC BY 4.0).

http://creativecommons.org/licenses/by/4.0/ (c) (i)

\begin{abstract}
Objectives: To examine demographics, clinical correlates, sputum AFB (acid fast bacilli) smear grading DOTS (Directly Observed Therapy Short Course) uptake, and drug resistance in a cohort of newly-diagnosed, smear positive pulmonary tuberculosis (TB) patients with respect to HIV status at baseline, and compare smear conversion rates, side effects and mortality after two months. Design: A prospective study among 54 HIV positive and 41 HIV negative pulmonary TB patients. Data were collected via face-to-face interviews, review of medical records, and lab tests. Results: HIVTB co-infected patients, though more symptomatic at baseline, showed more improvement in their symptoms compared to HIV-uninfected TB patients at followup. The HIV co-infected group had more prevalent perceived side effects, and sputum smear positivity was marginally higher compared to the HIV negative group at follow-up. Mortality was higher among the HIV-infected group. Both groups had high rates of resistance to first-line anti-tubercular drugs, particularly isoniazid. There was no significant difference in the drug resistance patterns between the groups. Conclusions: Prompt initiation and provision of daily regimens of ATT (Anti-Tubercular treatment) along with ART (Anti-Retroviral treatment) via ART centers is urgently needed in India. As resistance to ART and/or ATT is directly linked to medication non-adherence, the use of counseling, regular reinforcement, early detection and appropriate intervention strategies to tackle this complex issue could help prevent premature mortality and development of resistance in HIV-TB co-infected patients. The high rate of isoniazid resistance might preclude its use in India as prophylaxis for latent TB in HIV infected persons as per the World Health Organization $(\mathrm{WHO})$ guideline.
\end{abstract}




\section{Keywords}

Pulmonary TB, HIV, Anti-Tubercular Drug Resistance

\section{Introduction}

India has the highest burden of tuberculosis (TB) in the world, with an estimated incidence of 2.2 million cases out of a global incidence of 9 million cases [1]. The prevalence of sputum smear-positive pulmonary TB is 2.27 per thousand compared to 5.05 per thousand of all forms of tuberculosis in India, and the average annual incidence of smear-positive cases is 84 per 100,000 [2]. HIV prevalence among incident TB patients is about 6 percent [3].

Through the Revised National TB Control Program (RNTCP), the Government of India provides free anti-tubercular treatment (ATT) known as Directly Observed Treatment, Short-course DOTS, a thrice weekly regimen delivered through state run and private sector providers [3]. Category 1 (CAT 1) DOTS is intended for new cases and consists of two months of intensive phase treatment with isoniazid (H), Rifampin (R), Pyrazinamide (Z), and Ethambutol (E), followed by four months of $\mathrm{H}$ and R. Category 2 (CAT 2) DOTS is for retreatment cases and has two months of HRZES ( $S$ = Streptomycin), one month of HRZE, and five months of HRE [3]. Patients who are adherent but do not achieve sputum smear conversion within two months following ATT initiation, require extended treatment [3] [4]. Sputum smear positivity after five months is considered to be failed treatment [3] [4]. Due to the enhanced survival benefits, it is recommended that HIV co-infected individuals receive anti-retroviral therapy (ART) regardless of CD4+ cell count soon after ATT initiation [5] [6].

Resistance to ATT has become a serious threat to TB control, with India harboring the second largest number of multi-drug resistant (resistance to $\mathrm{H}$ and $\mathrm{R}$ ) TB (MDRTB) cases [7] [8]. The prevalence of MDRTB reflects the efficiency of TB management by health care providers from the public (RNTCP) and private sector as well as their collaborative efforts.

There are very few studies comparing the demographics, symptoms, DOTS uptake, side effects, and ATT adherence on pulmonary TB patients based on their HIV status [9] [10]. Also, given the slow growth of mycobacterium in culture (6 - 8 weeks), challenges with tracking reports are not being readily available, and the high cost, Drug Susceptibility Testing (DST) is not a routine practice. Only a few studies have compared sputum microscopy/culture conversion as an interim indicator for final treatment outcomes in relation to HIV status [11]-[14]. Some studies have shown that HIV infection is associated with low TB bacillary density in the sputum, higher culture conversion rates and a positive association between CD4T lymphocyte count and bacillary density [13] [14]. Other studies, especially those from India, have not shown a relationship between CD4-T lymphocyte count and bacillary density [11] [12] [15]. This current study aims to fill this gap in the literature by first examining these factors, including drug resistance 
patterns, in a cohort of newly diagnosed sputum Acid Fast Bacilli (AFB) smear positive pulmonary TB patients, both with HIV co-infection, and without HIV co-infection. Our second aim is to look at differences in symptoms, ATT side effects, smear conversion rates and mortality between these groups after two months.

\section{Methods}

\subsection{Setting and Sample}

Potential participants were referred to the study by staff of the pulmonary and general medicine outpatient departments, inpatient wards, the ART center, and the community HIV care center at St John's Medical College Hospital. These patients had clinical symptoms suggestive of pulmonary TB. Newly detected smear positive pulmonary TB patients from the referral sites and those who had definite radiological evidence of pulmonary TB pending smear results were included.

Written informed consent approved by the Institute Ethics Committee at St John's Medical College Hospital was obtained from all participants. For patients whose sputum tests were not already completed, researchers collected two sputum AFB smear samples, one spot and one early morning sample for testing [16]. Participants were considered eligible for the study if they were 18 years of age or older, willing to participate, and had one or more sputum smear samples test positive for AFB.

Participants were interviewed face-to-face for approximately one hour, and a sputum sample was tested for AFB culture and sensitivity. Those with unknown HIV status were screened for HIV infection per the National AIDS Control Organization (NACO) guidelines [17]. CD4 T cell counts were collected for all HIV-infected participants, if a test had not been conducted within the past month.

A one-month follow-up interview was conducted to examine improvement in symptoms, side effects and changes in ATT/ART medications, and to provide patients with AFB culture reports. Wherever possible, a two month post-intensive phase AFB smear report was collected from the RNTCP treatment cards, patient records, registers, or from the patients themselves.

Ninety-eight participants were enrolled in the study, of which three participants who were sputum smear and culture negative were removed; data of two participants whose AFB smears were negative but cultures subsequently grew Mycobacterium Tuberculosis were retained. Hence data analysis was done on 95 participants; 54 HIV-infected and 41 -uninfected.

\subsection{Measures}

\subsubsection{Demographics}

Participant age, gender, marital status, employment, education and residence were recorded.

\subsubsection{Symptoms and Side Effects}

At baseline, participants indicated the symptoms they had experienced from a list of 
common TB symptoms (e.g. cough, fever, hemoptysis). At follow-up, a list of ATT side effects (e.g., nausea, vomiting, jaundice) was added. The number of endorsed symptoms and side effects were calculated.

\subsubsection{ATT/ART Medications}

Participants were asked about medications consumed, whether they were on DOTS, had changes to ATT/ART, where their medications were procured and who paid for their drugs. ART adherence was assessed using a Visual Analogue Scale (VAS) [18]. For ATT they were asked daily/weekly details of medications consumed as the drugs were recently started.

\subsubsection{Blood, Sputum Collection and Drug Susceptibility Testing}

We collected $5 \mathrm{ml}$ of blood from each HIV positive participant for CD4 count (flow cytometry) testing. HIV negative participants were screened by Enzyme linked immunosorbent assay (ELISA) [17]. Sputum samples from each patient were collected in sterile containers and transported to the laboratory or stored at $4^{\circ} \mathrm{C}$ if a delay was anticipated. The sputum smear bacillary load was graded as scanty, $1+, 2+, 3+$ per WHO/ RNTCP [3] [19] guidelines. Samples for culture were decontaminated and inoculated to the Mycobacterium Growth Indicator tube (Micro-MGIT) for growth and identification. DST was performed for Rifampicin $(40 \mu \mathrm{g} / \mathrm{ml})$, Isoniazid ( $1 \mu \mathrm{g} / \mathrm{ml})$, Ethambutol (2 $\mu \mathrm{g} / \mathrm{ml}$ ) and Streptomycin $(4 \mu \mathrm{g} / \mathrm{ml})$ using lyophilized drugs (Becton Dickinson Sparks $\mathrm{MD})$.

\subsection{Statistical Analysis}

For demographic, clinical correlates and DST data, univariate descriptive statistics were calculated as appropriate. Differences between groups were analyzed by $\chi^{2}$, Fisher's exact test or logistic regression for categorical variables, and Mann-Whitney U-test or t-test for continuous variables, using SPSS Version 16 software. A two-tailed p-value $<0.05$ was considered statistically significant.

\section{Results}

\subsection{Demographics}

As shown in Table 1, nearly three-quarters of participants were male, and a majority was Hindu, married, and had children. The median age was 35 years. HIV-infected patients were less educated $(\mathrm{p}<0.001)$ and had a lower median income than the uninfected group (Rs. 2000 vs. 4500, $\mathrm{p}=0.012$ ).

\subsection{Clinical Correlates, DOTS Uptake and Past History of TB}

As shown in Table 2, most patients presented with cough (96.8\%), followed by fever (87.1\%), weight loss (82.8\%) and night sweats (77.4\%). The HIV + TB group was more symptomatic than the TB only group (mean no. of symptoms 5.8 vs. 4.4, resp., p < 0.001). Overall DOTS uptake was $74.7 \%$, with marginally $(\mathrm{p}=0.074)$ fewer participants in the HIV infected group (50\%) than in the uninfected group (73.2\%) on CAT1 DOTS. 
Table 1. Demographic characteristics of the sample.

\begin{tabular}{|c|c|c|c|c|c|c|c|}
\hline \multirow[b]{2}{*}{ Characteristic } & \multicolumn{2}{|c|}{ All } & \multicolumn{2}{|c|}{$\mathrm{HIV}+\mathrm{TB}$} & \multicolumn{2}{|c|}{ TB only } & \multirow[b]{2}{*}{ p-value } \\
\hline & $\mathrm{n}$ & $\%$ & $\mathrm{n}$ & $\%$ & $\mathrm{n}$ & $\%$ & \\
\hline Gender & & & & & & & 0.521 \\
\hline Male & 70 & 73.7 & 41 & 75.9 & 29 & 70.7 & \\
\hline Female & 24 & 25.3 & 12 & 22.2 & 12 & 29.3 & \\
\hline Hijra & 1 & 1.1 & 1 & 1.9 & 0 & 0.0 & \\
\hline Place of residence & & & & & & & 0.304 \\
\hline Bangalore & 41 & 43.2 & 30 & 55.6 & 22 & 53.7 & \\
\hline Other Karnataka & 32 & 33.7 & 18 & 33.3 & 10 & 24.4 & \\
\hline Other state & 22 & 23.2 & 6 & 11.1 & 9 & 22.0 & \\
\hline Education & & & & & & & 0.000 \\
\hline None & 19 & 20.0 & 12 & 22.2 & 7 & 17.1 & \\
\hline$<4$ years & 18 & 18.9 & 17 & 31.5 & 1 & 2.4 & \\
\hline $4-9$ years & 23 & 24.2 & 6 & 11.1 & 17 & 41.5 & \\
\hline$\geq 10$ years & 35 & 36.8 & 19 & 35.2 & 16 & 39.0 & \\
\hline Marital status & & & & & & & 0.639 \\
\hline Married & 73 & 76.8 & 42 & 77.8 & 31 & 75.6 & \\
\hline Single & 18 & 18.9 & 9 & 16.7 & 9 & 22.0 & \\
\hline Widowed & 4 & 4.2 & 3 & 5.6 & 1 & 2.4 & \\
\hline Lives alone & 18 & 18.9 & 14 & 25.9 & 4 & 9.8 & 0.046 \\
\hline Has children & 63 & 66.3 & 38 & 70.4 & 25 & 61.0 & 0.337 \\
\hline \multirow[t]{2}{*}{ Hindu } & 81 & 85.3 & 50 & 92.6 & 31 & 75.6 & 0.021 \\
\hline & median & IQR & median & IQR & median & IQR & \\
\hline Age, years & 35 & $30-43$ & 35 & $32-41$ & 35 & $25-53$ & 0.889 \\
\hline $\begin{array}{l}\text { Income, Rupees } \\
\text { (if any, } \mathrm{n}=85 \text { ) }\end{array}$ & 3000 & $1000-5000$ & 2000 & $1000-4625$ & 4500 & $1500-6000$ & 0.012 \\
\hline
\end{tabular}

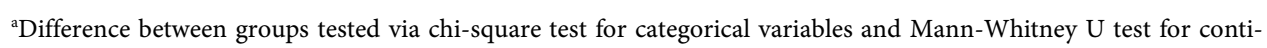
nuous variables.

Nineteen percent of HIV infected participants and $9.8 \%$ of uninfected participants were onCAT2 DOTS, and $31.5 \%$ versus $17.1 \%$, respectively, were on other daily regimens. Nearly one in three participants in either group had a previous history for TB ( $\mathrm{p}=$ 0.873) with 15 HIV infected participants (27.8\%) and 12 uninfected participants (29.3\%) having previously been treated for TB.

\subsection{HIV Infection and ART}

The majority ( $\mathrm{n}=41 / 54,76 \%)$ of the HIV infected patients reported getting tested for persistent illness, seven (13\%) because their spouse tested positive, six (11.1\%) on rou- 
Table 2. TB related variables.

\begin{tabular}{|c|c|c|c|c|c|c|c|c|}
\hline \multirow[b]{2}{*}{ Characteristic } & \multirow{2}{*}{$\frac{\text { Available }}{\mathrm{n}}$} & \multicolumn{2}{|c|}{ All } & \multicolumn{2}{|c|}{$\mathrm{HIV}+\mathrm{TB}$} & \multicolumn{2}{|c|}{ TB only } & \multirow{2}{*}{ p-value } \\
\hline & & $\mathrm{n}$ & $\%$ & $\mathrm{n}$ & $\%$ & $\mathrm{n}$ & $\%$ & \\
\hline History of TB & 95 & 27 & 28.4 & 15 & 27.8 & 12 & 29.3 & 0.873 \\
\hline TB symptoms: & 93 & & & & & & & \\
\hline Cough & & 90 & 96.8 & 51 & 92.2 & 39 & 97.5 & 0.731 \\
\hline Fever & & 81 & 87.1 & 51 & 96.2 & 30 & 75.0 & 0.003 \\
\hline Night sweats & & 72 & 77.4 & 45 & 84.9 & 27 & 67.5 & 0.047 \\
\hline Shortness of breath & & 69 & 74.2 & 46 & 86.8 & 23 & 57.5 & 0.001 \\
\hline Chest pain & & 59 & 63.4 & 43 & 81.1 & 16 & 40.0 & 0.000 \\
\hline Blood in sputum & & 34 & 36.6 & 24 & 45.3 & 10 & 25.0 & 0.044 \\
\hline Weight loss & & 77 & 82.8 & 47 & 88.7 & 30 & 75.0 & 0.084 \\
\hline Symptoms, mean (SD) & & 5.2 & $(1.4)$ & 5.8 & $(1.3)$ & 4.4 & $(1.2)$ & 0.000 \\
\hline TB regimen & 95 & & & & & & & 0.074 \\
\hline DOTS cat 1 & & 57 & 60.0 & 27 & 50.0 & 30 & 73.2 & \\
\hline DOTS cat 2 & & 14 & 14.7 & 10 & 18.5 & 4 & 9.8 & \\
\hline Other & & 24 & 25.3 & 17 & 31.5 & 7 & 17.1 & \\
\hline Sputum AFB at baseline & 95 & & & & & & & 0.638 \\
\hline Negative $^{\mathrm{b}}$ & & 2 & 2.1 & 1 & 1.9 & 1 & 2.4 & \\
\hline Scanty & & 13 & 13.7 & 5 & 9.3 & 8 & 19.5 & \\
\hline $1+$ & & 39 & 41.1 & 24 & 44.4 & 15 & 36.6 & \\
\hline $2+$ & & 22 & 23.2 & 12 & 22.2 & 10 & 24.4 & \\
\hline $3+$ & & 19 & 20.0 & 12 & 22.2 & 7 & 17.1 & \\
\hline 2 mo. FU sputum smear positive & 32 & 11 & 34.4 & 9 & 47.7 & 2 & 15.4 & 0.128 \\
\hline
\end{tabular}

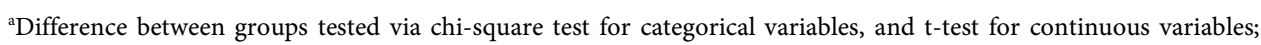
${ }^{\mathrm{b}}$ These patients grew Mycobacterium Tuberculosis in culture.

tine evaluation and one (1.9\%) for high risk behavior. Twenty-one (38.9\%) HIV infected participants were newly diagnosed, 24 (44.4\%) were within five years (median: 1 year, IQR. 0 - 4 yrs). Forty participants (74.1\%) were on ART at baseline. The majority were on $\mathrm{d} 4 \mathrm{t}$ (stavudine) + 3TC (lamivudine) + NVP (nevirapine) or Efavirenz (57.5\%) and $37.5 \%$ were on AZT (zidovudine) + 3TC + NVP or EFV. The median CD4+ count of the HIV-infected group was 125/ $\mu$ l (IQR: 82 - 195). There was no relationship between CD4+ count and mortality or past history of TB.

\subsection{Alcohol, Smoking and Co-Morbidities}

Among the men, overall 37 (52.9\%) were smokers and 41 (58.6\%) used alcohol with no significant difference between the groups $(p=0.417$ and $p=0.617)$. Nine $(17 \%)$ of the HIV infected participants versus eight (20\%) of the uninfected patients had a history of diabetes $(\mathrm{p}=0.720)$. None had a history of drug abuse. 


\subsection{Symptoms and Side Effects at Follow-Up}

Comparing Table 3 to Table 1, it shows that, in general, there was an improvement in symptoms at follow-up except for chest pain and hemoptysis. A comparison of the number of TB symptoms endorsed at baseline and 1 month follow-up, showed that the mean (SD) difference in symptoms endorsed in the HIV+ group was 0.63 (1.63) fewer symptoms, which was a significant decrease $(\mathrm{p}=0.016)$, while the HIV-group had 0.30 (2.3) more symptoms at follow-up ( $\mathrm{p}=0.459)$. Perceived side effects at 1 month followup were significantly higher in the HIV+ group, on average, than in the HIV- group (mean 8.0 vs. $5.9, \mathrm{p}=0.042$ ).

Table 3. Side effects of TB Treatment after 1 month.

\begin{tabular}{|c|c|c|c|c|c|c|c|}
\hline & \multicolumn{2}{|c|}{ All $(\mathrm{n}=78)$} & \multicolumn{2}{|c|}{$\mathrm{HIV}+\mathrm{TB}(\mathrm{n}=44)$} & \multicolumn{2}{|c|}{ TB only $(\mathrm{n}=34)$} & \multirow[b]{2}{*}{ p-value } \\
\hline & $\mathrm{n}$ & $\%$ & $\mathrm{n}$ & $\%$ & $\mathrm{n}$ & $\%$ & \\
\hline \multicolumn{8}{|l|}{ Symptoms: } \\
\hline Fever & 63 & 80.8 & 37 & 84.1 & 26 & 76.5 & 0.563 \\
\hline Night sweats & 51 & 65.4 & 25 & 56.8 & 26 & 76.5 & 0.094 \\
\hline Persistent cough & 68 & 87.2 & 40 & 90.9 & 28 & 82.4 & 0.317 \\
\hline Expectoration & 54 & 69.2 & 28 & 63.6 & 26 & 76.5 & 0.323 \\
\hline Blood in sputum & 37 & 47.4 & 22 & 50.0 & 15 & 44.1 & 0.653 \\
\hline Difficulty breathing & 49 & 62.8 & 30 & 68.2 & 19 & 55.9 & 0.346 \\
\hline Chest pain & 52 & 66.7 & 35 & 79.5 & 17 & 50.0 & 0.008 \\
\hline \multicolumn{8}{|l|}{ Perceived side effects } \\
\hline Jaundice & 43 & 55.1 & 28 & 63.6 & 15 & 44.1 & 0.110 \\
\hline Skin rash & 48 & 61.5 & 30 & 68.2 & 18 & 52.9 & 0.241 \\
\hline Tingling/numb fingers/toes & 33 & 42.3 & 25 & 56.8 & 8 & 23.5 & 0.005 \\
\hline Nausea/vomiting & 42 & 53.8 & 25 & 56.8 & 17 & 50.0 & 0.648 \\
\hline Stomach pain/cramps & 44 & 56.4 & 28 & 63.6 & 16 & 47.1 & 0.171 \\
\hline Giddy/loss of balance & 46 & 59.0 & 28 & 63.6 & 18 & 52.9 & 0.363 \\
\hline Decreased urine output & 30 & 38.5 & 18 & 40.9 & 12 & 35.3 & 0.646 \\
\hline Joint pain & 42 & 53.8 & 27 & 61.4 & 15 & 44.1 & 0.171 \\
\hline Headache & 47 & 60.3 & 27 & 61.4 & 20 & 58.5 & 1.000 \\
\hline Swelling in feet & 30 & 38.5 & 21 & 47.7 & 9 & 26.5 & 0.065 \\
\hline Swelling neck/groin/axilla & 27 & 34.6 & 20 & 45.5 & 7 & 20.6 & 0.031 \\
\hline Difficulty seeing & 24 & 30.8 & 17 & 38.6 & 7 & 20.6 & 0.137 \\
\hline Difficulty hearing & 16 & 20.5 & 10 & 22.7 & 6 & 17.6 & 0.778 \\
\hline Weakness in limbs & 23 & 29.5 & 17 & 38.6 & 6 & 17.6 & 0.050 \\
\hline Other & 3 & 3.8 & 2 & 4.5 & 1 & 2.9 & 1.000 \\
\hline $\begin{array}{l}\text { Total no. symptoms } \\
\text { endorsed: mean (SD) }\end{array}$ & 6.4 & $(4.4)$ & 7.3 & $(4.3)$ & 5.1 & $(4.4)$ & 0.029 \\
\hline
\end{tabular}

${ }^{\text {a} B a s e d ~ o n ~ F i s h e r ' s ~ e x a c t ~ t e s t ~ f o r ~ f r e q u e n c i e s ~ a n d ~ o n ~ t-t e s t ~ f o r ~ m e a n . ~}$ 


\subsection{Changes in ART/ATT Medications}

Among the HIV infected group, five participants who were ART naïve [20] were started on triple drug regimens and there were three NRTI substitutions. Ten participants on nevirapine were substituted with efavirenz. One stopped ATT; two were substituted with fluoroquinolones and a third on RZES daily changed to CAT1 DOTS in the HIV+ group, and one participant on HRZE daily to CAT2 DOTS in the HIV- group. Eight out of the 40 participants who were on ART at baseline reported $\leq 80 \%$ ART adherence in the past month. As participants had just started ATT at the time of assessment, the overall adherence rates were almost $100 \%$ for ATT.

\subsection{Month Post-Intensive Phase Follow up and Sputum Reports}

Out of the 32 sputum smear samples available at 2 month follow up, nine (47.7\%) from the HIV infected group and two (15.4\%) from the -uninfected group remained positive $(\mathrm{p}=0.13)$. By two months, from the data available on all the participants, eight $(15.7 \%)$ of the TB + HIV group were known to be deceased, versus one $(2.4 \%)$ in the TB only group, a significant difference in mortality $(\mathrm{p}=0.04)$.

\subsection{Resistance to ATT}

Sputum samples were cultured for 77 participants (81\%). The remaining 18 were not cultured due to technical problems (e.g. lack of sputum cups, lack of refrigeration in transport, $n=11)$, insufficient quantities of sputum $(n=2)$ and not returning for follow-up $(\mathrm{n}=5)$. As shown in Table 4, 70.1\% grew Mycobacterium Tuberculosis, $2.6 \%$ grew Mycobacterium other than TB, and there was no growth in the remaining 27.3\%. Of the samples with available DST reports, $61.1 \%$ were resistant to Isoniazid, $31.5 \%$ to Rifampicin and MDRTB was observed in $24.5 \%$. Eleven percent were resistant to all drugs tested (RHES). The odds of MDRTB were three times higher in the HIV-uninfected group than in the HIV group, controlling for history of TB (AOR $=3.14,95 \% \mathrm{CI}$ $0.74-13.38)$. However this difference was not statistically significant $(\mathrm{p}=0.122)$.

\section{Discussion}

To our knowledge, this is the first time that symptoms, DOTS uptake, side effects, drug adherence, resistance and mortality were studied prospectively by HIV status in a cohort of exclusively smear positive pulmonary TB patients in India. We observed that the HIV+ group was more symptomatic for TB at baseline. Their symptoms significantly improved, but they had more adverse reactions compared to the HIV-uninfected group at one month follow-up. The higher average number of symptoms in HIV+ positive patients could be due to delayed reporting to the health care provider as symptoms are attributed to HIV disease, increased prevalence of smear negative pulmonary, extrapulmonary or disseminated forms of TB [5] [21] [22] and diagnostic uncertainty due to ART-related side effects or other opportunistic infections. Drug interactions, shared drug toxicities of ATT/ART, or Immune Reconstitution Inflammatory Syndrome (IRIS) could have contributed to the large number of perceived side effects in the HIV 
Table 4. Resistance testing results.

\begin{tabular}{lccccccc}
\hline & \multicolumn{2}{c}{ All } & \multicolumn{2}{c}{ HIV + TB } & \multicolumn{2}{c}{ TB only } \\
\hline & $\mathrm{n}$ & $\%$ & $\mathrm{n}$ & $\%$ & $\mathrm{n}$ & $\%$ & $\mathrm{p}^{- \text {value }^{\mathrm{a}}}$ \\
\hline Cultured samples: & $(\mathrm{n}=77)$ & & $(\mathrm{n}=40)$ & & $(\mathrm{n}=37)$ & & 0.284 \\
No growth & 21 & 27.3 & 14 & 35.0 & 7 & 18.9 & \\
MOTT & 2 & 2.6 & 1 & 2.5 & 1 & 2.7 & \\
M-TB & 54 & 70.1 & 25 & 62.5 & 29 & 78.4 & \\
Resistant to: & $(\mathrm{n}=54):$ & & $(\mathrm{n}=25)$ & & $(\mathrm{n}=29)$ & & \\
Rifampicin (R) & 17 & 31.5 & 7 & 28.0 & 10 & 34.5 & 0.770 \\
Isoniazid (H) & 33 & 61.1 & 14 & 56.0 & 19 & 65.5 & 0.579 \\
Streptomycin (S) & 15 & 27.8 & 7 & 28.0 & 8 & 27.6 & 1.000 \\
Ethambutol (E) & 20 & 37.0 & 10 & 40.0 & 10 & 34.5 & 0.780 \\
H + R (=MDR) & 13 & 24.1 & 4 & 16.0 & 9 & 31.0 & 0.223 \\
H + R + S + E & 6 & 11.1 & 2 & 8.0 & 4 & 13.8 & 0.675 \\
Any drug & 40 & 74.1 & 19 & 76.0 & 21 & 72.4 & 1.000 \\
\hline
\end{tabular}

MDR, multi-drug resistance; MOTT, Mycobacterium other than TB; M-TB, Mycobacterium Tuberculosis; ${ }^{a}$ Based on Fisher's exact test for frequencies.

co-infected group [5] [21] [22].

About three quarters of our respondents were on thrice weekly DOTS regimens, with marginally $(p=0.074)$ fewer of the HIV infected group on CAT1. The WHO guidelines suggest that HIV patients co-infected with TB should be treated with daily regimens in the initial intensive phase [6] [23] [24]. A recent meta-analysis found higher rates of ATT failure, and relapses or death due to TB if the initial intensive phase was administered thrice a week instead of daily, or if ART was not initiated [25]. This situation could be improved by linking the RNTCP with the National AIDS Control Program [3] to provide and dispense daily ATT along with ART for HIV co-infected participants in their ART center.

The HIV + TB group was less literate and had a smaller median income than the HIV-group, which mirrors the socio-demographics of HIV + TB patients in the rest of the world [26] [27]. Twenty percent of our HIV positive participants were non-adherent to ART. Most studies [28] [29] report increased non-adherence in co-infected patients with better adherence to ART than to ATT [28]. Though there were higher numbers of HIV infected smear positives at two month follow-up, the difference was not statistically significant. A recent study on smear conversion rates had only two HIV+ patients, both continuing to remain smear positive even at the end of the fifth month of treatment [30].

We observed very high rates of drug resistance overall, particularly with Isoniazid, which is consistent with other studies from Karnataka [7] [31]-[33] and elsewhere in India [34] [35] and has implications for the rationale of the current WHO recommen- 
dation of Isoniazid prophylaxis (IPT) for latent TB in the HIV infected [36] [37]. Furthermore, substantial emerging evidence challenges the preconceived paradigm of latent/active TB disease against the backdrop of HIV infection [38]. As observed worldwide [12] [22]-[24], there was a significant difference in mortality between the HIVinfected and -uninfected group at two months follow-up.

Our study has its limitations. The small size and the regional nature of the sample may not allow generalization of results to the whole country. The low number of two month follow-up sputum smear reports may have resulted in inadequate power to find significant differences in smear conversion rates between the groups.

\section{Conclusion}

We found that HIVTB co-infected patients were more symptomatic at baseline. They had more perceived side effects-possibly due to shared drug toxicities of ATT/ART, drug interactions or IRIS and a higher prevalence of sputum smear positivity and mortality at follow-up, compared to HIV uninfected TB participants. There was no significant difference in drug resistance patterns between the groups, with high rates of resistance to any first line anti-tubercular drug, particularly isoniazid. Prompt initiation and daily regimens of ATT along with ART, for HIV co-infected participants from their ART center will be a step forward to meeting the WHO guideline with respect to daily ATT. The very high rate of isoniazid resistance found in this and other studies across India [23] [31]-[35] might preclude its use as prophylaxis for latent TB in HIV infected individuals. As resistance to ART and/or ATT is directly linked to medication nonadherence, counseling regarding adherence to both regimens, regular reinforcement on follow-up, early detection and appropriate intervention strategies to tackle non-adherence could help prevent mortality and development of resistance to ATT in the HIVTB co-infected [39] [40].

\section{Acknowledgements}

We would like to thank the staff of the internal, pulmonary medicine departments and the DOTS Center for their support. We thank the Chetana team members for supervising the data collection and management. We sincerely thank the technicians of the Department of Microbiology for the entire laboratory work and help in keeping track of the reports. We thank the management and staff of Snehadaan for kindly permitting use of their facility for study purposes. We gratefully acknowledge support from the University of California, San Francisco's International Traineeships in AIDS Prevention Studies (ITAPS), U.S. NIMH, R25MH064712 and University of California, Berkeley and San Francisco, AIDS International Training and Research Program (AITRP), Fogarty International Center, D43TW000003. Further funding was provided by NIH grant R01-MH095659-01 (PI: M. Ekstrand). Most importantly, we are ever thankful to the patients who generously contributed their time to help us better understand treatment related issues. 


\section{Author Contributions}

SC and ME designed the study and developed the study instruments; SC implemented the study, conceptualized and drafted the manuscript; $\mathrm{EH}$ performed the statistical analysis and created the tables. $\mathrm{ME}$ and $\mathrm{EH}$ critically evaluated and revised the paper; BM performed and drafted the laboratory component. All authors participated in the data interpretation, manuscript revisions and have read and approved the final manuscript.

\section{References}

[1] WHO (2015) Global Tuberculosis Report 2015. World Health Organization, Geneva. http://www.who.int/tb/publications/global_report/en/

[2] Chakraborty, A.K. (2004) Epidemiology of Tuberculosis: Current Status in India. Indian Journal of Medical Research, 120, 248-276.

[3] Revised National Tuberculosis Control Programme (2005) Technical and Operational Guidelines for Tuberculosis Control. Government of India Directorate General of Health Services, New Delhi.

http://tbcindia.nic.in/pdfs/Technical\%20\&\%20Operational\%20guidelines\%20for\%20TB\%2 0Control.pdf

[4] API Consensus Expert Committee (2006) API TB Consensus Guidelines 2006: Management of Pulmonary Tuberculosis, Extra-Pulmonary Tuberculosis and Tuberculosis in Special Situations. Journal of the Association of Physicians of India, 54, 219-234.

[5] Venkatesh, K.K., Swaminathan, S., Andrews, J.R. and Mayer, K.H. (2011) Tuberculosis and HIV Co-Infection: Screening and Treatment Strategies. Drugs, 71, 1133-1152.

http://dx.doi.org/10.2165/11591360-000000000-00000

[6] WHO (2012) A Guide to Monitoring and Evaluation for Collaborative TB/HIV Activities. World Health Organization, Geneva. http://www.who.int/tb/publications/2012/tb_hiv_policy_9789241503006/en/

[7] Gaude, G.S., Hattiholli, J. and Kumar, P. (2014) Risk Factors and Drug-Resistance Patterns among Pulmonary Tuberculosis Patients in Northern Karnataka Region, India. 2014. Nigerian Medical Journal, 55, 327-332. http://dx.doi.org/10.4103/0300-1652.137194

[8] WHO (2008) Anti Tuberculosis Drug Resistance in the World: The WHO/IUATLD Global Project on Anti Tuberculosis Drug Resistance Surveillance. Fourth Global Report, World Health Organization, Geneva.

[9] Sharma, S.K., Manish Soneja, K.T.P. and Ranjan, S. (2014) Clinical Profile \& Predictors of Poor Outcome of Adult HIV Tuberculosis Patients in a Tertiary Care Centre in North India. Indian Journal of Medical Research, 139, 154-160.

[10] Pradeep, S. (2011) The Situation of HIV/M. Tuberculosis Co-Infection in India. The Open Infectious Diseases Journal, 5, 51-59.

[11] Banu Rekha, V.V., Balasubramanian, R., Swaminathan, S., et al. (2007) Sputum Conversion at the end of Intensive Phase of Category-1 Regimen in the Treatment of Pulmonary Tuberculosis Patients with Diabetes Mellitus or HIV Infection: An Analysis of Risk Factors. Indian Journal of Medical Research, 126, 452-458.

[12] Swaminathan, S., Deivanayagam, C.N., Rajasekaran, S., et al. (2008) Long Term Follow up of HIV-Infected Patients with Tuberculosis Treated with 6-Month Intermittent Short Course Chemotherapy. The National Medical Journal of India, 21, 3-8. 
[13] Mugusi, F., Villamor, E., Urassa, W., Saathoff, E., Bosch, R.J. and Fawzi, W.W. (2006) HIV Co-Infection, CD4 Cell Counts and Clinical Correlates of Bacillary Density in Pulmonary Tuberculosis. International Journal of Tuberculosis and Lung Disease, 10, 663-669.

[14] Joloba, M.L., Johnson, J.L., Namale, A., et al. (2000) Quantitative Sputum Bacillary Load during Rifampin-Containing Short Course Chemotherapy in Human Immunodeficiency Virus-Infected and Non-Infected Adults with Pulmonary Tuberculosis. International Journal of Tuberculosis and Lung Disease, 4, 528-536.

[15] Singhal, S., Mahajan, S.N., Diwan, S.K., Gaidhane, A. and Quazi, Z.S. (2011) Correlation of Sputum Smear Status with CD4 Count in Cases of Pulmonary Tuberculosis and HIV Co-Infected Patients: A Hospital Based Study in a Rural Area of Central India. Indian Journal of Tuberculosis, 58, 108-112.

[16] TB-C India Directorate General of Health Services (2009) Diagnosis of Smear Positive Pulmonary TB-New Guidelines, effective from 1 April 2009. Ministry of Health and Family Welfare India Eds.

http://tbcindia.nic.in/pdfs/1b\%20-\%20Diagnosis\%20of\%20smear\%20positive\%20pulmonar y\%20TB.pdf

[17] NACO (2007) Guidelines for HIV Testing. Ministry of Health and Family Welfare, New Delhi.

http://naco.gov.in/upload/Policies\%20\&\%20Guidelines/5-GUILDELINES\%20FOR\%20HIV \%20TESTING.pdf

[18] Ekstrand, M.L., Chandy, S., Heylen, E., Steward, W. and Singh, G. (2010) Developing Useful Highly Active Antiretroviral Therapy Adherence Measures for India: The Prerana Study. Journal of Acquired Immune Deficiency Syndromes, 53, 415-416. http://dx.doi.org/10.1097/QAI.0b013e3181ba3e4e

[19] WHO (1998) Laboratory Services in TB Control, Part II: Microscopy. World Health Organization, Geneva. http://whqlibdoc.who.int/hq/1998/WHO_TB_98.258_\%28part2\%29.pdf

[20] AIDS Clinical Trials Group. Trials Open for Enrollment. Department of Health and Human Services, NIH. https://actgnetwork.org/trials_open_enrollment

[21] Dierberg, K.L. and Chaisson, R.E. (2013) HIV-Associated Tuberculosis: Update on Prevention and Treatment. Clinics in Chest Medicine, 34, 217-228. http://dx.doi.org/10.1016/j.ccm.2013.02.003

[22] Mo, P., Zhu, Q., Teter, C., et al. (2014) Prevalence Drug Induced Hepatotoxicity and Mortality among Patients Multi-Infected with HIV, Tuberculosis and Hepatitis Virus. International Journal of Infectious Diseases, 28, 95-100. http://dx.doi.org/10.1016/j.ijid.2014.06.020

[23] Sethi, S., Mewara, A., Dhatwalia, S.K., et al. (2013) Prevalence of Multidrug Resistance in Mycobacterium tuberculosis Isolates from HIV Seropositive and Seronegative Patients with Pulmonary Tuberculosis in North India. BMC Infectious Diseases, 13, 137. http://dx.doi.org/10.1186/1471-2334-13-137

[24] Swaminathan, S., Narendran, G., Venkatesan, P., et al. (2010) Efficacy of a 6-Month versus 9-Month Intermittent Treatment Regimen in HIV-Infected Patients with Tuberculosis: A Randomized Clinical Trial. American Journal of Respiratory and Critical Care Medicine, 181, 743-751. http://dx.doi.org/10.1164/rccm.200903-0439OC

[25] Khan, F.A., Minion, J., Pai, M., Royce, S., Burman, W. and Harries, A.D. (2010) Treatment of Active Tuberculosis in HIV-Coinfected Patients: A Systematic Review and Meta-Analysis. Clinical Infectious Diseases, 50, 1288-1299. http://dx.doi.org/10.1086/651686

[26] Córdoba-Doña, J.A., Novalbos-Ruiz, J.P., Suárez-Farfante, J., Andérica-Frías, G. and Esco- 
lar-Pujolar, A. (2012) Social Inequalities in HIV-TB and Non-HIV-TB Patients in Two Urban Areas in Southern Spain: Multilevel Analysis. International Journal of Tuberculosis and Lung Disease, 16, 342-347. http://dx.doi.org/10.5588/ijtld.11.0137

[27] Nibardo, P.-A., Mata-Marin, J.A., Gaytan-Martinez, Jesus., Huerta-Garcia, G. and AcostaCazares, B. (2013) Clinical and Sociodemograzphic Risk Factors for Tuberculosis in Human Immunodeficiency Virus Infected Patients. American Journal of Infectious Diseases, 9, 142147. http://dx.doi.org/10.3844/ajidsp.2013.142.147

[28] Daftary, A., Padayatchi, N. and O’Donnell, M. (2014) Preferential Adherence to Antiretroviral Therapy over Tuberculosis Treatment: A Qualitative Study of Drug-Resistant TB/HIV co-Infected Patients in South Africa. Global Public Health, 9, 1107-1116. http://dx.doi.org/10.1080/17441692.2014.934266

[29] Naidoo, P., Peltzer, K., Louw, J., Matseke, G., Mchunu, G. and Tutshana, B. (2013) Predictors of Tuberculosis (TB) and Antiretroviral (ARV) Medication Non-Adherence in Public Primary Care Patients in South Africa: A Cross Sectional Study. BMC Public Health, 13, 396. http://dx.doi.org/10.1186/1471-2458-13-396

[30] Parikh, R., Nataraj, G., Kanade, S., Khatri, V. and Mehta, P. (2012) Time to Sputum Conversion in Smear Positive Pulmonary TB Patients on Category I DOTS and Factors Delaying It. Association of Physicians of India, 60, 22-26.

[31] Mishra, B., Rockey, S.M., Gupta, S., Srinivasa, H. and Muraleedharan, S. (2012) MultiDrug-Resistant Tuberculosis: The Experience of an Urban Tertiary Care Hospital in South India Using Automated BACTEC 460 TB. Tropical Doctor, 42, 35-37. http://dx.doi.org/10.1258/td.2011.110247

[32] Burugina Nagaraja, S., Satyanarayana, S., Chadha, S.S., et al. (2011) How Do Patients Who Fail First-Line TB Treatment but Who Are Not Placed on an MDR-TB Regimen Fare in South India? PLoS ONE, 6, e25698. http://dx.doi.org/10.1371/journal.pone.0025698

[33] Nagaraja, C., Shashibhushan, B.L., Sagar, C., Asif, M. and Manjunath, P.H. (2011) Resistance Pattern in Drug-Resistant Pulmonary Tuberculosis. Journal of Postgraduate Medicine, 57, 181-183. http://dx.doi.org/10.4103/0022-3859.85197

[34] Kandi, S., Prasad, S.V., Sagar Reddy, P.N., et al. (2013) Prevalence of Multidrug Resistance among Retreatment Pulmonary Tuberculosis Cases in a Tertiary Care Hospital, Hyderabad, India. Lung India, 30, 277-279. http://dx.doi.org/10.4103/0970-2113.120599

[35] Magee, M.J., Blumberg, H.M., Broz, D., et al. (2012) Prevalence of Drug Resistant Tuberculosis among Patients at High-Risk for HIV Attending Outpatient Clinics in Delhi, India. Southeast Asian Journal of Tropical Medicine and Public Health, 43, 354-363.

[36] WHO (2011) Guidelines for Intensified Tuberculosis Case-Finding and Isoniazid Preventive Therapy for People Living with HIV in Resource-Constrained Settings. World Health Organization, Geneva, Switzerland. http://www.who.int/tb/challenges/hiv/ICF_IPTguidelines/en/

[37] Gupta, S., Abimbola, T., Date, A., et al. (2014) Cost-Effectiveness of the Three P $s$ for HIVITB and ART to Prevent TB among People Living with HIV. International Journal of Tuberculosis and Lung Disease, 18, 1159-1165. http://dx.doi.org/10.5588/ijtld.13.0571

[38] Lawn, S.D., Wood, R. and Wilkinson, R.J. (2011) Changing Concepts of "Latent Tuberculosis Infection" in Patients Living with HIV Infection. Clinical and Developmental Immunology, 2011, Article ID: 980594. http://dx.doi.org/10.1155/2011/980594

[39] Nieuwlaat, R., Wilczynski, N., Navarro, T., Hobson, N., Jeffery, R., Keepanasseril, A., Agoritsas, T., Mistry, N., Iorio, A., Jack, S., Sivaramalingam, B., Iserman, E., Mustafa, R.A., Jedraszewski, D., Cotoi, C. and Haynes, R.B. (2013) Interventions for Enhancing Medication 
Adherence. Cochrane Database of Systematic Reviews, Article Number: CD000011. http://www.thecochranelibrary.com

[40] Rueda, S., Park-Wyllie, L.Y., Bayoumi, A., Tynan, A.-M., Antoniou, T., Rourke, S. and Glazier, R. (2006) Patient Support and Education for Promoting Adherence to Highly Active Antiretroviral Therapy for HIV/AIDS. Cochrane Database of Systematic Reviews, Article Number: CD001442. http://www.thecochranelibrary.com

Submit or recommend next manuscript to SCIRP and we will provide best service for you:

Accepting pre-submission inquiries through Email, Facebook, LinkedIn, Twitter, etc. A wide selection of journals (inclusive of 9 subjects, more than 200 journals)

Providing 24-hour high-quality service

User-friendly online submission system

Fair and swift peer-review system

Efficient typesetting and proofreading procedure

Display of the result of downloads and visits, as well as the number of cited articles Maximum dissemination of your research work

Submit your manuscript at: http://papersubmission.scirp.org/ 